\title{
Islet transplantation: the quest for an ideal source
}

\author{
Nidal A. Younes, ${ }^{a}$ Jean-Manuel Nothias, ${ }^{\text {b }}$ Marc R. Garfinkel ${ }^{\mathrm{b}}$ \\ From the a Department of Surgery, University of Jordan, Amman, Jordan and the bepartment of Surgery, University of Chicago, Chicago, Illinois, \\ USA \\ Correspondence and reprints: Nidal Younes, MD · Department of Surgery, Faculty of Medicine, University of Jordan · PO Box 13024, Amman \\ 11942, Jordan · F: +962-6-535-3388 · niyounes@ju.edu.jo · Accepted for publication May 2008 \\ Ann Saudi Med 2008; 28(5): 325-333
}

The progress of islet transplantation as a new therapy for patients with diabetes mellitus depends directly upon the development of efficient and practical immunoisolation methods for the supply of sufficient quantities of islet cells. Without these methods, large scale clinical application of this therapy would be impossible. Two eras of advances can be identified in the development of islet transplantation. The first was an era of experimental animal and human research that centered on islet isolation procedures and transplantation in different species as evidence that transplanted islets have the capability to reverse diabetes. The second was the era of the Edmonton protocol, when the focus became the standardization of isolation procedures and introduction of new immunosuppressive drugs to maintain human allograft transplantation. The quest for an alternative source for islets (xenographs, stem cells and cell cultures) to overcome the shortage of human islets was an important issue during these eras. This paper reviews the history of islet transplantation and the current procedures in human allotransplantation, as well as different types of immunoisolation methods. It explores novel approaches to enhancing transplantation site vascularity and islet cell function, whereby future immunoisolation technology could offer additional therapeutic advantages to human islet allotransplantation.

$\mathrm{S}$ ince the first attempt to isolate intact and viable pancreatic islets, ${ }^{1}$ there have been two principal landmarks in the history of islet transplantation. First, isolation of islets from the pancreas has changed from the use of tedious and complicated techniques to the semi-automated Ricordi method. ${ }^{2}$ The introduction of the Ricordi chamber, controlled pancreas distension with low-endotoxin Liberase and the COBE continuous purification system have shortened the time of isolation and improved both the yield and purity of isolated islets, paving the way for more extensive clinical trials. ${ }^{3-6}$ Second, there was a dramatic development in the field of human islet transplantation with the introduction of the Edmonton protocol in July of 2000 by Shapero et al. ${ }^{7}$ This development is ongoing, especially in Canada and certain centers in the United States and Europe with a $44 \%$ success rate for being free of exogenous insulin in attempted candidates after one year of follow-up. ${ }^{8}$ However, large scale clinical application of the protocol is mainly restricted by the shortage of hu- man islet cells; for a single recipient of islet cells, one or two pancreata from deceased donors are required for successful allotransplantion. ${ }^{9}$ Consequently, the availability of islet cell supply will be enough for only a small percentage of patients with type 1 diabetes. ${ }^{9,10}$ It is therefore clear that other sources of islets such as animal islets, stem cells or cell cultures are needed to replace human islets and to advance islet transplantation as a valid option for patients with diabetes. ${ }^{11-13}$

Recent developments in isolation and preservation of islet cells from animal sources have opened a possible new islet source. ${ }^{14,15}$ However, these sources would cause a significant immune response that would result in the destruction of transplanted islets and would require immunosuppressive drugs to maintain transplanted islets. Immunosuppressive drugs have significant side effects and their long-term safety is not fully understood. The concept of "immunoisolation," in which the islets are protected from the host immune response by advanced encapsulation procedures, may be a solution to this dilemma. ${ }^{16,17}$ 
Besides reviewing the two eras of islet transplantation and the current procedure for human islet transplantation, this review addresses the concept of immunoisolation, whereby animal sources for islets (xenografts) could offer additional therapeutic advantages to those offered by human islets for patients with diabetes.

\section{The era of experimental animal and human research (1969-2000)}

The first successful method for isolation of islets from rodent pancreata was described in 1969 by Paul E. Lacy who later demonstrated successful islet transplantation in rodents. ${ }^{18}$ The success of Lacy's studies on islet cell transplantation in animals was an important proof of principal that islet transplantation can reverse diabetes in animals and could possibly be used to treat patients with diabetes.

Following the success of Lacy's experiments, the main preoccupation of islet cell researchers was to improve the isolation techniques and to enhance the yield from the isolation process in different animal species. However, subsequent trials on islet isolation in large animals did not achieve the same success rate seen in rodents as the methods proved to be ineffective for the more complex pancreas in large animals. ${ }^{2}$ It was soon recognized that new techniques for islet isolation must be evaluated in a large animal model in order to simulate the complex nature of the human pancreas in terms of both tissue composition and consistency. Numerous laboratories around the world began exhaustive efforts using the canine pancreas as a preclinical model for developing new methods for human isolation. However, this proved to be difficult and tedious, contributing markedly to the delay in the development of human islet isolation procedures. ${ }^{19}$

Early attempts at isolation of human islets were highly traumatic via ineffective techniques and were gradually replaced by the Ricordi semi-automated method in the late 1980s. The introduction of the Ricordi chamber, ${ }^{3}$ controlled pancreas distension, ${ }^{4}$ lowendotoxin Liberase (Roche Diagnostics Corporation, Indianapolis, IN, USA), ${ }^{5}$ and the COBE continuous purification system (Gambro BCT, Inc., Lakewood, $\mathrm{CO}, \mathrm{USA})^{6}$ during this period has rapidly replaced all previous procedures. This shift towards more efficient and faster isolation procedures has been achieved through intense, innovative endeavors without debate or controversy. The advantages of the Ricordi chamber and subsequent refinements were all too apparent during this era in improving the outcome of human islet isolation process. ${ }^{19-21}$

\section{The era of the Edmonton protocol after 2000}

Until the year 2000, allotransplantation of human islets, which presents the additional barriers of rejection and the potential toxicity of immunosuppressive agents, had limited success. A review of all islet transplants performed and reported to the International Islet Transplant Registry (IITR) between 1990 to 1998 revealed insulin independence rates of $12 \%$ and $8 \%$ at 1 -week and 1 -year, respectively. ${ }^{22}$ The publication of a clinical report from the University of Alberta in Edmonton, Canada, in July of 2000 describing 7 patients with type 1 diabetes who underwent islet transplantation and remained independent of exogenous insulin at a mean follow-up of 11.9 months was a major breakthrough in the field of islet transplantation. ${ }^{7}$ The relative success of the Edmonton group was attributed to transplantation of a sufficient number of islets, with islets derived from two or three donor pancreata and a steroid-free immunosuppressive regimen. The new immunosuppressive regimen and isolation protocol used for this trial later became known as "the Edmonton protocol". This report changed the perception of human islet transplantation from a procedure with limited success into something filled with potential and success, which resulted in renewed worldwide enthusiasm and optimism for the future of islet allograft transplantation. ${ }^{19}$

Following the release of the initial report from Edmonton, at least three major multicenter initiatives were undertaken to reproduce and expand upon the University of Alberta's initial success. First, the Immune Tolerance Network (ITN) identified and funded ten centers around the world, seven of which are in North America, to participate in a multicenter trial of the Edmonton protocol. Second, the National Institutes of Health (NIH) proposed six and later funded nine US centers to become "Islet Cell Resources (ICRs) for the isolation, purification, and characterization of human pancreatic islet cells for transplantation into diabetic patients. ${ }^{23}$ Third, the Clinical Islet Transplant Consortium, also funded by the NIH, allocated $\$ 75$ million to five centers to conduct a large-scale clinical trial of islet transplantation and to translate the practice of islet transplantation from clinical research to a standard of care. The era of Edmonton protocol can be considered the period of optimism that triggered not only intense research and emotion, but that also led to significant private and academic interest in islet cell transplantation and defined the basic minimum requirements for islet cell therapy. 


\section{Allotransplantation of human islets}

Infusion of an adequate amount of islet tissue is the most important factor in the achievement of successful islet transplantation. According to many centers, adequate islet yield is obtained if at least 5000 islet equivalents (IEq, defined as a standardized islet volume assuming an "ideal" islet of 150 micron diameter) per kilogram recipient body weight are taken from a single processed pancreas. ${ }^{24}$

Cadaver donors in the age range of 25 to 45 years without a history of diabetes have generally been used for islet transplantation. Other donor variables correlated with a successful outcome (sufficient yield) include a body mass index $>25$ and a local procurement team, whereas those correlated with an unsuccessful outcome were rising serum glucose, longer duration of cardiac arrest, and cold ischemia time. ${ }^{25,26}$ Following procurement, preservation of the pancreas for islet transplantation is carried out using the two-layer cold storage method (TLM), which employs a University of Wisconsin solution (UW) and perfluorocarbon (PFC) with pre-oxygenation. ${ }^{27,28}$ Islet isolation is performed in specialized centers with Current Good Manufacturing Policies (CGMP) facilities in the US and around the world. Isolation is performed by a semi-automated technique described by Ricordi. ${ }^{3}$ The technique involves cannulation of the pancreatic duct followed by distension with digestive enzymes (collagenase and neutral protease). The pancreas is then minced into variably sized pieces and placed in a specialized chamber containing marbles and a screen filtering the outlet to allow for mechanical and enzymatic digestion. Once the islets are free of acinar tissue but still intact, the digestion is stopped by cooling and thus inactivating the solution. The slurry of digested pancreas is washed several times and recombined prior to purification via density gradient centrifugation in a Ficoll gradient. Final islet preparations are then assessed prior to release for transplant to ensure adequacy of islet yield, sterility, viability and sometimes function. At the University of Chicago, prerelease criteria are typical of most programs and include a minimum yield of $5000 \mathrm{IEq} / \mathrm{kg}$ recipient body weight, a negative gram stain, a maximum endotoxin level of 5 endotoxin units per $\mathrm{kg} /$ recipient, $70 \%$ viability, and a maximum tissue volume of $10 \mathrm{cc}$. The purified islets are then infused into the recipient portal vein through sonographically and fluoroscopically guided percutaneous transhepatic portal vein puncture. Portal vein pressures are measured periodically throughout the procedure. ${ }^{29,30}$ Uncommon but observed complications from this procedure include inability to achieve access, portal venous hypertension, intra-ab- dominal bleeding, adjacent organ (e.g*, gallbladder) puncture, portal vein thrombosis, abdominal pain, nausea and transient elevations in transaminase levels. ${ }^{29-32}$ According to the Edmonton protocol, patients are maintained on a steroid-free immunosuppressive regimen after transplantation with minimal doses of tacrolimus (trough levels 3-6 ng/mL) and the use of two relatively more recent drugs: the mTOR inhibitor rapamycin and the interleukin-2 receptor blocker dacluzimab. A preliminary report published in 2003 from the ITN trial on 36 patients revealed an initial exogenous insulin-independence rate of $52 \%$, with two voluntary withdrawals due to immunosuppressive side effects, six graft losses, and inter-center variability in transplant success. ${ }^{33}$ The final results of this trial were similar to the preliminary report; $44 \%$ of subjects met the primary endpoint of insulin independence one year after the final infusion of islets, with only $31 \%$ of those remaining insulin independent at two years. ${ }^{8}$

The Edmonton group continues to have the largest single-center experience in the world. Their most recent published report describing the first 65 islet recipients transplanted by November 2004 shows that 44 achieved insulin independence at some time after islet transplant, but only $10 \%$ maintained insulin independence at 5 years. ${ }^{34}$ The median duration of insulin independence was 15 months, with an interquartile range of 6.2 to 25.5 months. Despite this, evidence of ongoing islet function as determined by positive $C$-peptide measurements was $80 \%$ at 5 years. Those recipients with continued islet function (insulin independence or positive C-peptide) had markedly improved $\mathrm{HbA}_{1 \mathrm{c}}$ compared with recipients who lost all detectable islet function (insulin independent: $6.4 \%$, C-peptide positive but not insulin independent: $6.7 \%$, C-peptide negative: $9 \%){ }^{34}$ Regardless of insulin independence, recipients with functioning islet allografts experienced less hypoglycemia as measured by a validated self-reported survey instrument and less glycemic liability. ${ }^{35}$ Despite the high rate of return to some degree of insulin dependence, these results suggest clinical benefit in terms of diabetes management in the majority of islet recipients.

\section{Alternative sources for human islets}

Among the factors that contributed to the successful outcome in the Edmonton experience was the use of effective immunosuppression and the fact that many of their transplanted patients received more that one infusion of islets, which requires multiple cadaveric pancreata for procurement. To overcome these problems new approaches have evolved such as stem cell therapy and immunoisolation techniques. Stem cell- 
based approaches to this problem have been thoroughly reviewed by Street et al. ${ }^{36}$ According to these authors, embryonic stem cells are theoretically attractive due to expandability, multipotentiality and potential non-immunogenicity, but have been limited by technical difficulties in obtaining homogeneous differentiation towards islet tissue. Although adult pancreatic ductal cells have received much attention as potentially harboring islet precursor cells, no specific cellular phenotype demonstrating endocrine capabilities has been defined. ${ }^{37}$

Several research groups around the world began exhaustive efforts to finding alternative sources for islets that would be cost effective and applicable for largescale islet transplantation. ${ }^{38,39}$ Because of the sequence homology between porcine and human insulin, pigs are considered an attractive alternative for human islets. Currently, pig cells are an established source for human therapeutics including insulin and heart valves. In theory, the use of porcine islet cells could provide an essentially unlimited supply of cells for transplantation. The major disadvantage of pig xenografts, however, is the possible risk of cross-species infection with porcine endogenous retroviruses, which might then adapt to human hosts and cause permanent infection. ${ }^{40,41}$ Some reports have shown that porcine endogenous retroviruses from porcine cell lines and lymphocytes can infect human cells in vitro. ${ }^{42}$ However, recent reports on neonatal porcine islets within alginate microcapsules transplanted in diabetic mice and non-diabetic cynomolgus monkeys did not show adverse effects or evidence of infection with porcine endogenous retroviruses or other endemic pig viruses. ${ }^{43}$ Furthermore, in ten Swedish patients and two patients from New Zealand who received porcine islet xenografts, none showed signs of porcine endogenous retrovirus infection. ${ }^{44,45}$ In spite of this progress, safe and effective immunoisolation of transplanted islets must be achieved before this promising new technology can lead to a dramatic shift in clinical practice.

\section{The concept of immunoisolation}

The success of large-scale clinical application of islet transplantation depends on three main factors: an unlimited supply of islets, an easy and safe standard transplantation procedure and the ability to maintain functioning islets without immunosuppressive drugs. ${ }^{38,39,46}$ Thus, the concept of immunoisolation of islets emerged as a possible technique to address all of these factors. Immunoisolation is based on the principle that transplanted tissue is protected from the host immune system by an artificial membrane, which allows the cells inside it to interact with body demands to maintain homeostasis. ${ }^{47,48}$ To be efficient and useful, immunoiso- lation should have a barrier compatible with the human body (inert). The barrier must also have pores of appropriate size to allow passage of oxygen, electrolytes, and nutrients, but not the cells or the antibodies of the immune system to avoid destruction of the islets. They should also be transplanted in an area that allows maximum homeostatic responses and the lowest potential risks to the host. ${ }^{48}$ The two main approaches for immunoisolation, macroencapsulation and microencapsulation will be described in this review. The advantages and pitfalls of these two approaches are discussed and compared with respect to their applicability to clinical islet transplantation.

\section{Macroencapsulation}

Several types of intravascular and extravascular macroencapsulation devices have been designed and evaluated over the past several years. The original biohybrid devices, which are anastomosed to the vascular system as AV shunts, were among the first immunoisolation methods. ${ }^{49}$ These intravascular devices used bundles of capillary fibers seeded with islets on their outside surfaces. ${ }^{50}$ However, several issues remain that appear to limit the therapeutic potential of these devices. Data suggested that the size and the shape of perfusion devices imposed a limitation on the amount of islet tissue that could be transplanted into a diabetic patient. Thrombosis and infection are additional problems that limited the long-term use of these devices. ${ }^{51}$

Extravascular macrocapsules are usually diffusion chambers transplanted at different sites and in different shapes. Cylindrical polyacrylonitril-polyvinyl chloride membrane chambers have shown the most significant progress. ${ }^{52}$ Bovine, canine and porcine islets transplanted within these chambers restored normoglycemia in diabetic rats for periods of several months to more than a year. ${ }^{52,53}$ Extravascular chambers have advantages over the intravascular because of the lower incidence of clotting complications and infection. ${ }^{48}$ However, the membranes used in these devices were relatively fragile and susceptible to breakage which required their complete removal from the transplantation site. ${ }^{54}$

\section{Microencapsulation}

Sodium alginate (ALG) microencapsulation was the first method used for immunoisolation of islets of Langerhans reported by Lim and Sun in $1980{ }^{55}$ Since then, several alternative materials such as polyethylene glycol membranes (PEG), agarose, tissue-engineered chondrocytes, polyacrylates and the sodium cellulose sulfate have been used with varying degrees of success ${ }^{56-59}$ In theory, microcapsules 


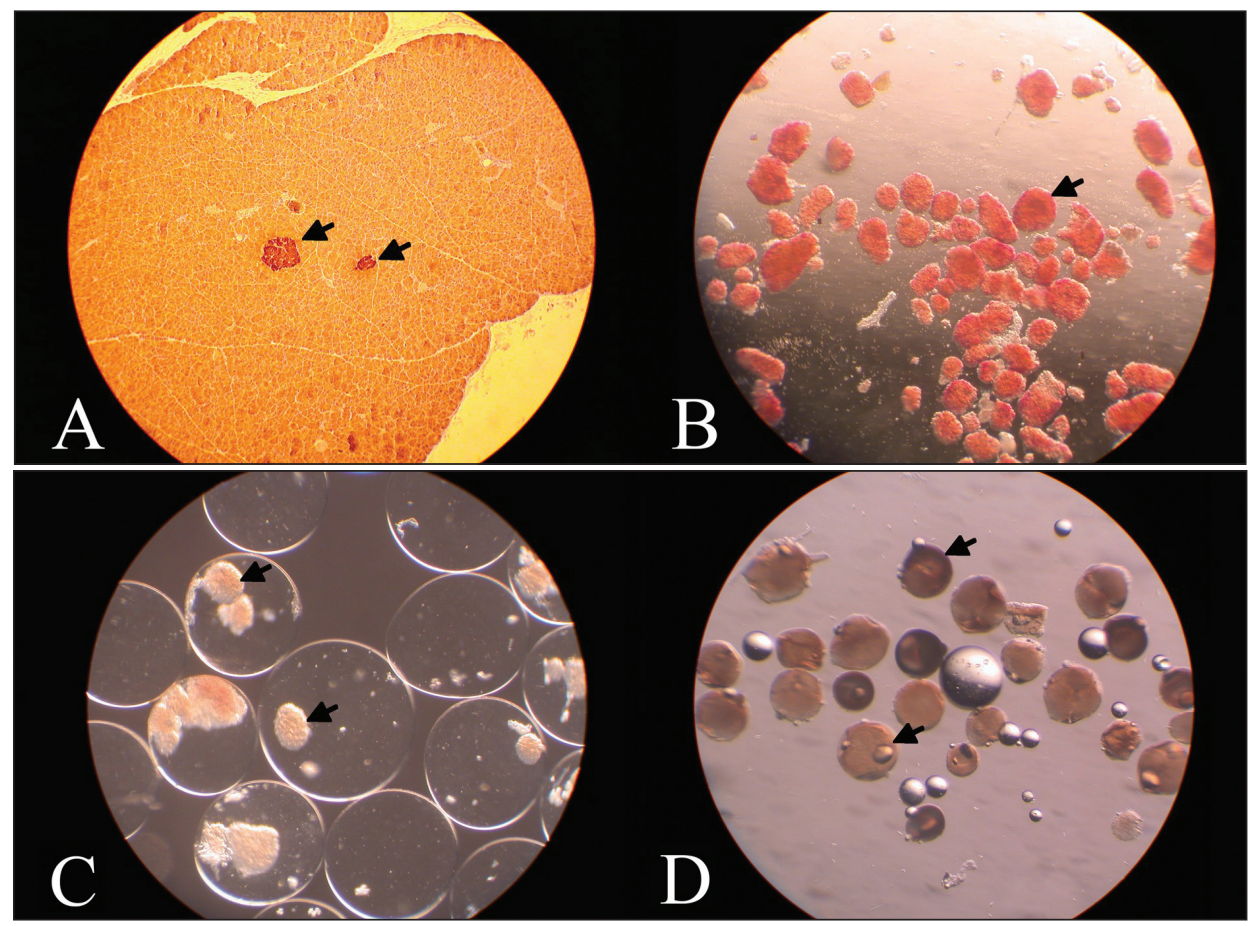

Figure 1.

Photomicrography

of rat islets of

Langerhans

distributed in

pancreatic tissue

(arrows) (A), rat

islets of Langerhans

1 day after isolation

(arrows) (B), rat

islets 1 day after ALG/

PLL encapsulation

(arrows) (C), and

rat islets 1 day after

PEG encapsulation

(arrows) (D) (original

magnification $\times 30$ ).

provide the greatest surface area-to-islet volume ratio for maximum diffusion capabilities as they are mechanically stable, durable, require uncomplicated manufacturing procedures and can be implanted easily into the recipient by an injection procedure (Figure 1). ${ }^{56} \mathrm{ALG}$ is often combined with poly L-lysine (ALG/PLL) to create an ionic multilayer membrane around an encapsulated islet, which provides control over membrane permeability ${ }^{60,61}$ ALG can be readily polymerized in aqueous solution via the addition of divalent cations such as calcium, magnesium or barium. Several studies have demonstrated the excellent in vitro viability of encapsulated islets. ${ }^{62,63}$ However, animal studies in chemically induced diabetic recipients have yielded varied results, with some studies having good long-term graft function while others had graft failure due to pericapsular fibrosis. ${ }^{64-68}$ The issue of fibrosis around the ALG capsules and necrosis of the islets as a result of insufficient nutrition has been the major problem causing the failure of encapsulated islet grafts. ${ }^{48,69}$

A few reports from Italian and American research teams have appeared in the literature describing successful results from clinical trials using ALG/PLL encapsulated islets of Langerhans. ${ }^{45,70,71}$ Although the published data provide proof of principal for a successful clinical application, there are many issues that need to be solved before this system can be considered as a therapy for diabetes. These issues are related to the islet cells being very sensitive to any kind of stress, and issues related to the nature, quality, size and shape of the capsules, as well as the optimal sites for transplantation. ${ }^{72,73}$ Currently, ALG microencapsulation is based on droplet generation by extrusion through a needle (Figure $2 \mathrm{~A})$. This is usually associated with inconsistencies in the thickness and the size of the alginate capsules. ${ }^{74}$ Typically, alginate capsules have outer diameters in the order of $750 \mu \mathrm{m}^{75}$ To overcome these problems, other materials have been tried and newer techniques of encapsulation have been suggested ${ }^{76,77}$ PEG as reported by Pathak et and Cruise et al appears to be the most promising in generating a small-size capsules and evenly coating the surface of islets. ${ }^{78,79}$

Regardless of how the biotechnical problems of microencapsulation are perceived, most private companies favor the use alginate for microencapsulation. Several companies have patented claims related to alginate microencapsulation in the past two decades: MicroIslet, Inc. (San Diego, CA, USA), Amcyte, Inc. (Santa Monica, CA, USA), Cerco Medical and Living Cell Technologies (Australia). The use of PEG in islet microencapsulation was validated by the Novocell and SprayGel companies. We have directed our efforts for several years at the University of Chicago to define the factors that influence the microencapsulated islets. To this end, we have been using ALG-PLL microencapsulation and PEG microencapsulation. We have also used two techniques for microencapsulation: droplet 
PANEL A

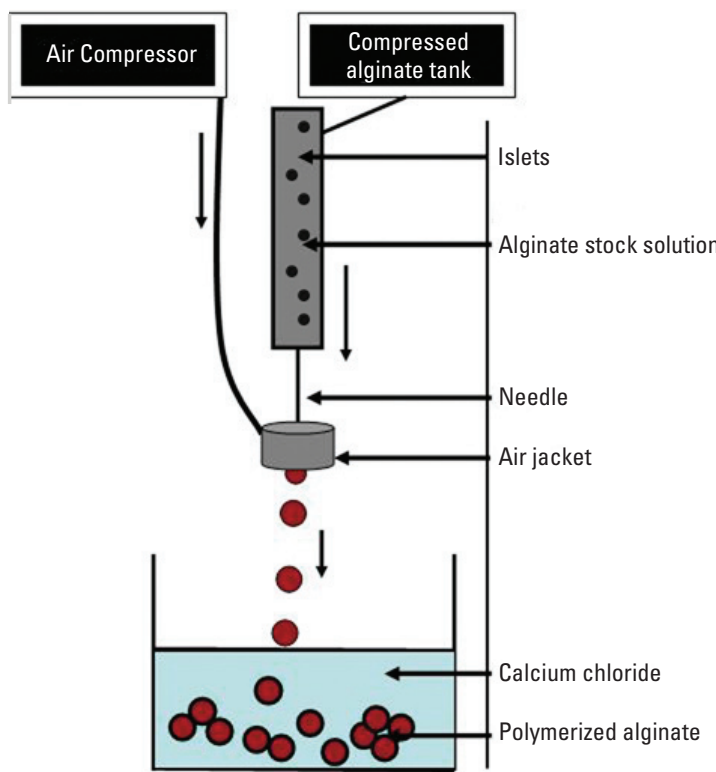

PANEL B

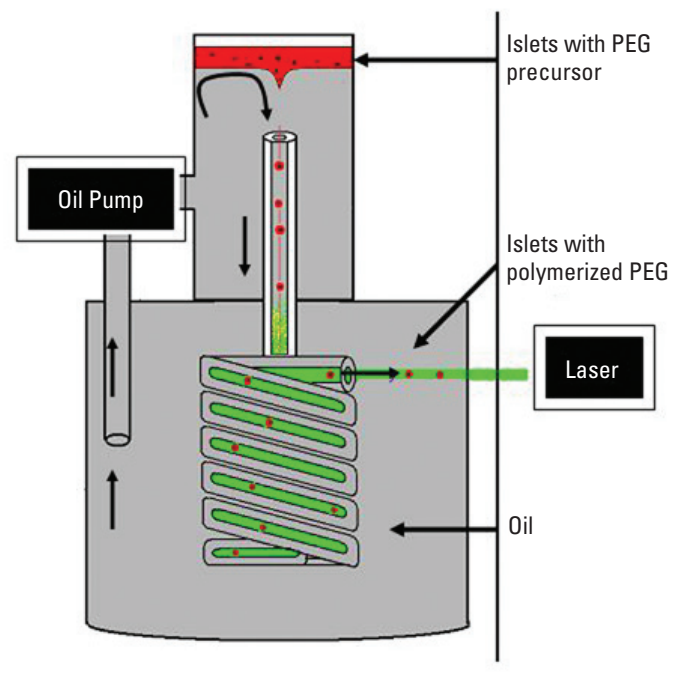

Figure 2. Schematic representation of ALG microencapsulation using the needle extrusion method (A). Schematic representation of PEG microencapsulation using the selective withdrawal particle-coating method (B).

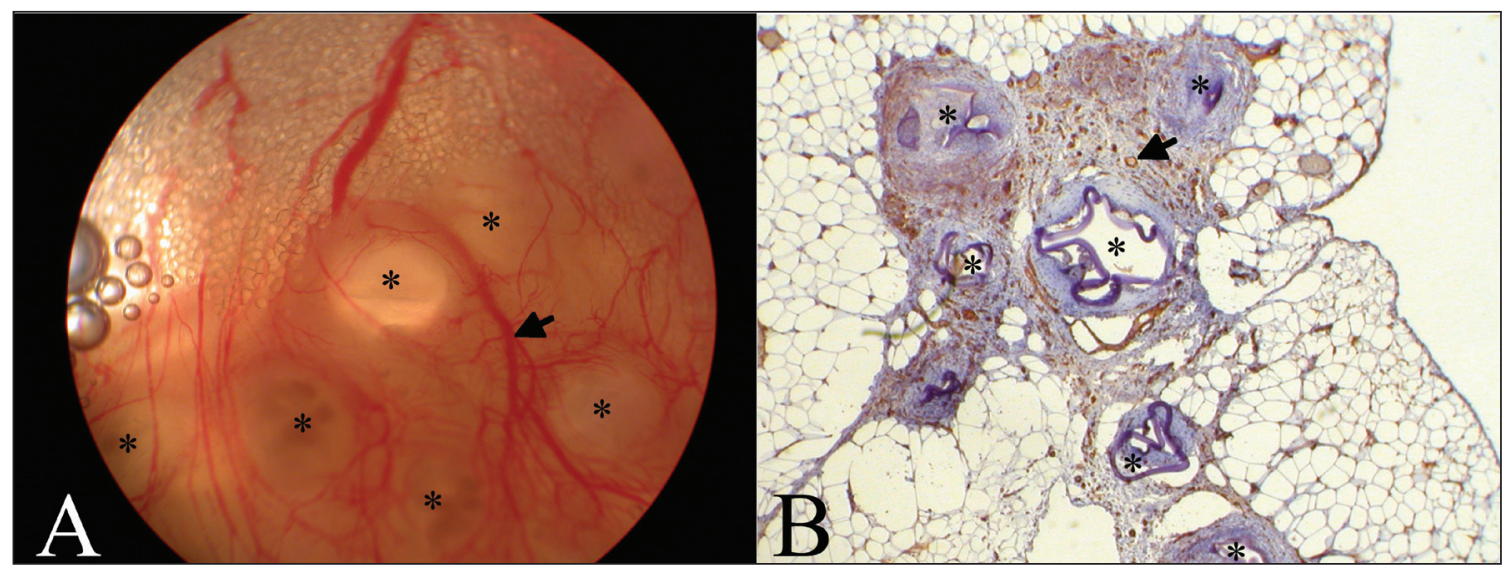

Figure 3. Macroscopic picture of rat omentum 1 month after transplantation with PDGF-enriched capsules (*). The arrows indicate neovascularization (A). Immunohistochemistry micrograph for endothelial markers showing marked vascularity around and through the alginate capsules (arrows) (B) (original magnification $\times 30$ ).

generation by extrusion through a needle for ALG microencapsulation and selective withdrawal particlecoating for PEG encapsulation (Figure 2B). Our objective was to improve the technique of encapsulation and the outcome of transplantation of microencapsulated islets to be a potential treatment of type 1 diabetes. We have also showed that the selective-withdrawal method can be used to generate encapsulated islets with regular shape and a size close to $20 \mu \mathrm{m} .{ }^{80}$ The clinical appli- cation of microencapsulation technology depends on further improvements in biocompatibility, the size of microcapsules and the efficiency of the microencapsulation process.

\section{Potential sites for islet cell transplantation}

The longevity of the transplanted islets and the functional performance rely on several features of the transplantation site. First, the site should be easily accessed 
with minimal risks to the patient. Second, the transplantation site must have the ability to support and nourish the islets immediately after transplantation. Third, because of the complex mechanisms which allow pancreatic cells to monitor and rapidly respond to the entro-insulinar stimulus response or the glucoseinduced stimulus-response, it is important that the site allow for close contact with the portal circulation. This is important to permit hepatic first-pass kinetics of insulin released from the transplanted islets. ${ }^{7}$ Fourth, the site should also provide the capacity to bear a large graft volume equivalent to approximately 3 to $5 \mathrm{cc}$ of fluid containing naked cells or 6 to $10 \mathrm{cc}$ of encapsulated islets. ${ }^{48}$ Unfortunately, it is difficult to find a site that combines all of these features together. Transplantation of islets into the liver was shown in 1973 to provide a physiological advantage by Kemp and his colleagues. ${ }^{81}$ Several other sites later were reported to allow successful islet transplantation, such as the spleen, pancreas, and the renal capsule. ${ }^{81-83}$ However, these sites can never carry critical volumes of more than 3 to $10 \mathrm{cc}$ of the naked or encapsulated islets required for human transplantation. ${ }^{48}$

To overcome this problem, we examined the concept of omental preparation and capsule optimization. Omental preparation with growth factors such as platelet-derived growth factor (PDGF) or vascular endothelial growth factor prior to transplantation could stimulate the development of enough vascularization of the omentum necessary for encapsulated islets. The omentum could also allow for transplantation of high volumes of islets, which can easily be injected and theoretically retrieved if necessary. After 4 weeks of trans- planting ALG encapsulated islets with PDGF, macroscopically we found more vessels over and in the omental pouch compared to the control sample (Figure 3A). Subsequent staining with CD31 (endothelial antibody marker) showed more vascularity among PDGF-treated samples (Figure 3B). We are also in the process of testing the effects of incretin peptide incorporation into the PEG encapsulation process. Our preliminary data has shown an improved glucose stimulation response in encapsulated islets treated with these hormones.

\section{Conclusion}

The shortage of human islets, concerns about cross infection between animal and humans in xenografting, and the extremely high expense of clinical studies on human microencapsulation have contributed to the slow progress in the clinical application of the microencapsulation approach. However, it is obvious that several advances have been made in immunoisolation of pancreatic islets over the past two to three decades. In view of the international effort in ongoing clinical trials of porcine microencapsulated islets recently launched in Russia and the US, one might expect an unlimited source of porcine islets in the near future. Hopefully, safer and more efficient immunoisolation techniques will be developed allowing patients with type 1 diabetes to benefit from this treatment.

\section{Acknowledgments}

Nidal Younes is a visiting research professor from the University of Jordan and is supported by a Fulbright research fellowship grant, Marc R. Garfinkel received research grants from the Juvenile Diabetes Research Foundation. 


\section{REFERENCES}

1. Lacy PE, Kostianovsky M. A method for isolation of intact islets of Langerhans from the rat pancreas. Diabetes. 1967;16:35-39.

2. Ricordi C. The automated method for islet isolation. In Pancreatic Islet Cell Transplantation 1892-1991: One Century of Transplantation fo Diabetes. Ricordi C, Ed. Austin, TX, R.G. Landes Company,1992, p.99-112.

3. Ricordi C, Lacy PE, Finke EH, Olack BJ, Scharp DW. Automated method for isolation of human pancreatic islets. Diabetes. 1988:37:413-420.

4. Lakey JR, Warnock GL, Shapiro AM, Korbutt GS Ao Z, Kneteman NM, et al. Intraductal collagenase delivery into the human pancreas using syringe loading or controlled perfusion. Cell Transplant. 1999:8:285-292

5. Linetsky E, Bottino R, Lehmann R, Alejandro R, Inverardi L, Ricordi C. Improved human islet isolation using a new enzyme blend, liberase. Diabetes. 1997;46:1120-1123.

6. Robertson GS, Chadwick DR, Contractor $H$ James RF, London NJ. The optimization of largescale density gradient isolation of human islets Acta Diabetol. 1993;30:93-98.

7. Shapiro AM, Lakey JR, Ryan EA, Korbutt GS Toth $E$, Warnock GL, et al. Islet transplantation in seven patients with type 1 diabetes mellitus using a glucocorticoid-free immunosuppressive regimen. N Engl J Med. 2000;27;343(4):230-8.

8. Shapiro AM, Ricordi C, Hering BJ, Auchinclos $\mathrm{H}$, Lindblad R, Robertson RP, et al. Internationa trial of the Edmonton protocol for islet transplantation. N Engl J Med. 2006;28;355(13):1318-30.

9. Nanji SA, Shapiro AM. Advances in pancreatic islet transplantation in humans. Diabetes Obes Metab. 2006;8(1):15-25

10. Lakey JR, Mirbolooki M, Shapiro AM. Curren status of clinical islet cell transplantation. Methods Mol Biol. 2006;333:47-104.

11. Bogdani M, Suenens K, Bock T, Pipeleers Marichal M, In't Veld P, Pipeleers D. Growth and functional maturation of beta-cells in implants of endocrine cells purified from prenatal porcine pancreas. Diabetes. 2005;54(12):3387-94.

12. Baharvand $H$, Jafary $H$, Massumi $M$, Ashtiani SK. Generation of insulin-secreting cells from human embryonic stem cells. The potential for stem cell therapy in diabetes. Pediatr Res. 2006:59/4 Pt 2):65R-73R

13. Jun HS, Yoon JW. Approaches for the cure of type 1 diabetes by cellular and gene therapy. Cur Gene Ther. 2005;5(2):249-62.

14. Yonekawa $Y$, Matsumoto $S$, Okitsu T, Arata $T$ Iwanaga $Y$, Noguchi $\mathrm{H}$ et al. Effective islet isolation method with extremely high islet yields from adult pigs. Cell Transplant. 2005:14(10):757-62.

15. Brandhorst $D$, Iken M, Brendel MD, Bretzel RG Brandhorst $\mathrm{H}$. Long-term preservation of the pig pancreas by a one-layer method for successfu islet isolation. Transplant Proc. 2005;37(1):229-30. 16. van Schilfgaarde $R$, de Vos P. Aspects of immunoprotection of islets. Transplant Proc. 1996;28(6):3516-7.

17. de Groot M, Keizer PP, de Haan BJ, Schuurs TA, Leuvenink HG, van Schilfgaarde $R$ et al. Microcapsules and their ability to protect islets against cytokine-mediated dysfunction. Transplant Proc. 2001;33(1-2):1711-2.

18. Ballinger WF, Lacy PE. Transplantation of intact pancreatic islets in rats. Surg. 1972;72(2):175-86.

19. Ricordi C. Islet transplantation: a brave new world. Diabetes. 2003;52(7):1595-603.

20. Gores PF, Najarian JS, Stephanian E, Lloveras JJ, Kelley SL, Sutherland DE. Insulin independence in type I diabetes after transplantation of unpurified islets from single donor with 15-deoxyspergualin. Lancet. 1993;341(8836):19-21.

21. Robertson RP. Pancreatic islet transplantation or diabetes: successes, limitations, and chalenges for the future. Mol Genet Metab. 2001;74(1 2):200-5.

22. Brendel $M$, Hering $B$, Schultz A, Bretzel $R$. International Islet Transplant Registry Report. Giessen, Germany, University of Giessen, 1999;1-20. 23. NCRR launches $\$ 10.4$ million initiative to create islet cell resource centers. Transplant News 2001;11(20):4.

24. Kobayashi N, Okitsu T, Lakey JR, Tanaka N. The current situation in human pancreatic islet transplantation: problems and prospects. J Artif Organs. 2004;7(1):1-8

25. Lakey JR, Warnock GL, Rajotte RV, SuarezAlmazor ME, Ao Z, Shapiro AMJ, et al. Variables in organ donors that affect the recovery of human islet of langerhans. Transplantation. 1996;61(7):1047-

26. Toso C, Oberholzer J, Ris F, Triponez F, Bucher $P$, Demirag $A$, et al. Factors affecting human islet of Langerhans isolation yields. Transplantation Proceedings. 2002:34(3):826-827.

27. Hering BJ, Matsumoto I, Sawada T, Nakano M, Sakai T, Kandaswamy R et al. Impact of two-layer pancreas preservation on islet isolation and transplantation. Transplantation. 2002;74:1813-1816.

28. Lakey JR, Tsujimura T, Shapiro AM, Kuroda Y Preservation of the human pancreas before islet isolation using a two-layer (UW solution-perfluorochemical) cold storage method. Transplantation. 2002;74:1809-1811.

29. Goss JA, Soltes G, Goodpator SE, Barth M, Lam $\mathrm{R}$, Brunicardi $\mathrm{FC}$, et al. Pancreatic islet transplantation: the radiologic approach. Transplantation. 2003;76(1):199-203

30. Casey JJ, Lakey JRT, Ryan EA, Paty BW, Owen $R, O^{\prime} K e l l y K$, et al. Portal venous pressure changes after sequential clinical islet transplantation Transplantation. 2002;74(7):913-915.

31. Ryan EA, Lakey JRT, Paty BW, Imes S, Korbutt GS, Kneteman NM, et al. Successful islet transplantation: continued insulin reserve provides long-term glycemic control. Diabetes. 2002;21(7):2148-2157.

32. Shapiro AMJ, Lakey JRT, Rajotte RV, Warnock GL, Friedlich MS, Jewell LD, et al. Portal vein thrombosis after transplantation of partially purified pancreatic islets in a combined human liver/ islet transplant. Transplantation. 1995;59(7):10601063

33. ITN. Preliminary Results of ITN Multicenter slet Transplant Trial Confirm Potential Patien Benefits, Underscore Steep Learning Curve. In: ITN News and Announcements; 2003.

34. Ryan EA, Paty BW, Senior PA, Bigam D, Alfadhli E, Kneteman NM, et al. Five-year followup after clinical islet transplantation. Diabetes. 2005;54(7):2060-2069

35. Ryan EA, Shandro T, Green K, Paty BW, Senior PA, Bigam D, et al. Assessment of the severity of hypoglycemia and glycemic lability in type 1 diabetic subjects undergoing islet transplantation. Diabetes. 2004;53(4):955-62.

36. Street CN, Sipione S, Helms L, Binette T, Rajotte RV, Bleackley RC, et al. Stem cell-based approaches to solving the problem of tissue supply for islet transplantation in type 1 diabetes. Int J Biochem Cell Biol. 2004;36:667-683.

37. Yalniz M, Pour PM. Are there any stem cells in the pancreas? Pancreas. 2005;31(2):108-18.

38. Robertson RP. Islet transplantation: travels up the learning curve. Curr Diab Rep. 2002;2(4):365-
39. Onaca N, Klintmalm GB, Levy MF. Pancreatic islet cell transplantation: a treatment strategy for type I diabetes mellitus. Nutr Clin Pract. 2004:19(2):154-64.

40. Patience C, Takeuchi Y, Weiss RA. Infection of human cells by an endogenous retrovirus of pigs. Nat Med. 1997;3:282-286.

41. Binette TM, Seeberger KL, Lyon JG, Rajotte RV, Korbutt GS. Porcine endogenous retroviral nucleic acid in peripheral tissues is associated with migration of porcine cells post islet transplant. Am J Transplant. 2004;4(7):1051-60.

42. Wilson CA, Wong S, Muller J, Davidson CE, Rose TM, Burd P. Type $C$ retrovirus released from porcine primary peripheral blood mononuclear cells infects human cells. J Virol. 1998;72: 30823087

43. Elliott RB, Escobar L, Tan PL, Garkavenko 0, Calafiore R, Basta P, et al. Intraperitoneal alginateencapsulated neonatal porcine islets in a placebocontrolled study with 16 diabetic cynomolgus primates. Transplant Proc. 2005;37(8):3505-8.

44. Heneine $W$, Tibell A, Switzer WM, Sandstrom $P$, Rosales GV, Mathews A, et al. No evidence of infection with porcine endogenous retrovirus in recipients of porcine islet-cell xenografts. Lancet. 1998;352:695-699.

45. Elliott RB, Escobar L, Garkavenko 0, Croxson MC, Schroeder BA, McGregor M, et al. No evidence of infection with porcine endogenous retrovirus in recipients of encapsulated porcine islet xenografts. Cell Transplant. 2000;9(6):895-901.

46. Kendall WF Jr, Collins BH, Opara EC. Islet cell transplantation for the treatment of diabetes mellitus. Expert Opin Biol Ther. 2001;1(1):109-19.

47. Ohgawara H. Strategies for immunoisolation in islet transplantation: challenges for the twenty-first century. J Hepatobiliary Pancreat Surg. 2000;7(4):374-9.

48. de Vos P, Hamel AF, Tatarkiewicz K. Considerations for successful transplantation of encapsulated pancreatic islets. Diabetologia. 2002;45(2):159-73

49. Sun AM, Parisius W, Healy GM, Vacek I, Macmorine $\mathrm{HG}$. The use, in diabetic rats and monkeys, of artificial capillary units containing cultured islets of Langerhans (artificial endocrine pancreas). Diabetes. 1977:26(12):1136-9.

50. Maki T, Lodge JP, Carretta M, Ohzato H, Borland KM, Sullivan SJ, et al. Treatment of severe diabetes mellitus for more than one year using a vascularized hybrid artificial pancreas. Transplantation. 1993;55(4):713-7.

51. Colton CK. Implantable biohybrid artificial organs. Cell Transplant. 1995;4(4):415-36.

52. Lanza RP, Borland KM, Lodge $P$, Carretta $M$, Sullivan SJ, Muller TE, et al. Treatment of severely diabetic pancreatectomized dogs using a diffusion-based hybrid pancreas. Diabetes. 1992;41(7):886-9.

53. Scharp DW, Swanson CJ, Olack BJ, Latta PP, Hegre OD, Doherty EJ, et al. Protection of encapsulated human islets implanted without immunosuppression in patients with type I or type II diabetes and in nondiabetic control subjects. Diabetes. 1994:43(9):1167-70

54. Lanza RP, Sullivan SJ, Chick WL. Perspectives in diabetes. Islet transplantation with immunoisolation. Diabetes. 1992:41(12):1503-10.

55. Lim F, Sun AM. Microencapsulated islets as bioartificial endocrine pancreas. Science. 1980;21;210(4472):908-10.

56. Uludag H, De Vos P, Tresco PA. Technology of mammalian cell encapsulation. Adv Drug Deliv 
Rev. 2000;42(1-2):29-64.

57. Pollok JM, Kolln PA, Lorenzen M, Torok $E_{\text {, }}$ Kaufmann PM, Kluth D, Bohuslavizki KH, Gundlach M, Rogiers X. Islets of Langerhans encap sulated with a tissue-engineered membrane of rat chondrocytes maintain insulin secretion and glucose-insulin feedback for at least 30 days in culture. Transplant Proc. 2001;33(1-2):1713-4.

58. Cruise GM, Hegre OD, Lamberti FV, Hage SR, Hill R, Scharp DS, et al. In vitro and in vivo performance of porcine islets encapsulated in interfacially photopolymerized poly(ethylene glycol) diacrylate membranes. Cell Transplant 1999;8(3):293-306.

59. Iwata H, Amemiya H, Matsuda T, Takano $\mathrm{H}$, Hayashi R, Akutsu T. Evaluation of microencapsulated islets in agarose gel as bioartificia pancreas by studies of hormone secretion in culture and by xenotransplantation. Diabetes. 1989:38 Suppl 1:224-5

60. King GA, Daugulis AJ, Faulkner P, Goosen MF. Alginate-polylysine microcapsules of controlled membrane molecular weight cut-off fo mammalian cell culture engineering. Biotechno Prog. 1987;3:231-240.

61. Vandenbossche GM, Van Oostveld P, Demeester J, Remon JP. The molecular weigh cut-off of microcapsules is determined by the reaction between alginate and polylysine. Biotechnol Bioeng. 1993:42:381-386.

62. Fan MY, Lum ZP, Fu XW, Levesque L, Tai IT, Sun AM. Reversal of diabetes in BB rats by transplantation of encapsulated pancreatic islets. Diabetes. 1990:39 (4):519-22.

63. De Vos P, De Haan BJ, Wolters GH, Strubbe JH, Van Schilfgaarde R. Improved biocompatibility but limited graft survival after purification of alginate for microencapsulation of pancreatic islets. Diabetologia. 1997;40(3):262-70.

64. De Vos P, De Haan B, Pater J, Van Schilfgaarde R. Association between capsule diam- eter, adequacy of encapsulation, and survival of microencapsulated rat islet allografts. Transplantation. 1996;15;62(7):893-9.

65. Soon-Shiong P, Feldman E, Nelson R, Heintz $R$, Yao 0 , Yao $Z$ et al. Long-term reversal of diabetes by the injection of immunoprotected islets. Proc Natl Acad Sci USA. 1993;15;90(12):5843-7. 66. King A, Lau J, Nordin A, Sandler S, Andersson $A$. The effect of capsule composition in the reversal of hyperglycemia in diabetic mice transplanted with microencapsulated allogeneic islets. Diabetes Technol Ther. 2003;50:653-663.

67. Clayton HA, James RF, London NJ. Islet microencapsulation: a review. Acta Diabetol. 1993;30:181-189

68. Krestow M, Lum ZP, Tai IT, Sun A. Xenotrans plantation of microencapsulated fetal rat islets. Transplantation. 1991;51:651-655.

69. De Vos P, Van Straaten JF, Nieuwenhuizen AG, de Groot M, Ploeg RJ, De Haan BJ, et al. Why do microencapsulated islet grafts fail in the absence of fibrotic overgrowth? Diabetes. 1999;48:1381-1388

70. Soon-Shiong $P$, Heintz RE, Merideth $N$, Yao $\mathrm{QX}$, Yao Z, Zheng T, et al. Insulin independence in a type 1 diabetic patient after encapsulated islet transplantation. Lancet. 1994;343(8903):950

71. Calafiore R, Basta G, Luca G, Lemmi A, Racanicchi L, Mancuso F, et al Standard technica procedures for microencapsulation of human islets for graft into nonimmunosuppressed patients with type 1 diabetes mellitus. Transplant Proc. 2006;38(4):1156-7.

72. De Vos P, Wolters GH, Fritschy WM, Van Schilfgaarde R. Obstacles in the application of microencapsulation in islet transplantation. Int J Artif Organs. 1993;16:205-212

73. Calafiore R. Alginate microcapsules for pancreatic islet cell immunoprotection struggle and progress towards the final cure for type 1 diabe- tes mellitus. Expert Opin Biol Ther. 2004;3:201

74. Wolters GH, Fritschy WM, Gerrits D, van Schilfgaarde R. A versatile alginate droplet generator applicable for microencapsulation of pancreatic islets. J Appl Biomater. 1991;3(4):281-6.

75. Kizilel S, Garfinkel M, Opara E. The bioartificial pancreas: progress and challenges. Diabetes Technol Ther. 2005;7(6):968-85.

76. Dupuy B, Gin H, Baquey C, Ducassou D. In situ polymerization of a microencapsulating medium round living cells. J Biomed Mater Res. 1988;22(11):1061-70.

77. Cohen I, Li H, Hougland JL, Mrksich M, Nagel SR. Using selective withdrawal to coat microparticles. Science. 2001;292(5515):265-7.

78. Pathak CP, Sawhney AS, Quinn CP, Hubbell JA. Polyimide-polyethylene glycol block copolymers: synthesis, characterization, and initial evaluation as a biomaterial. J Biomater Sci Polym Ed. 1994;6(4):313-23.

79. Cruise GM, Hegre OD, Scharp DS, Hubbell JA. A sensitivity study of the key parameters in the interfacial photopolymerization of polylethylene glycol) diacrylate upon porcine islets. Biotechnol Bioeng. 1998;57(6):655-65.

80. Wyman JL, Kizilel S, Skarbek R, Zhao X, Connors $M$, Dillmore WS, et al. Immunoisolating pancreatic islets by encapsulation with selective withdrawal. Small. 2007;3(4):683-90.

81. Kemp CB, Knight MJ, Scharp DW, Lacy PE, Ballinger WF. Transplantation of isolated pancreatic islets into the portal vein of diabetic rats. Nature. 1973;244(5416):447.

82. van Suylichem PT, Strubbe JH, Houwing $H_{\text {, }}$ Wolters GH, van Schilfgaarde R. Rat islet isograft function. Effect of graft volume and transplantation site. Transplantation. 1994:57(7):1010-7.

83. Andersson A, Korsgren O, Jansson L. Intraportally transplanted pancreatic islets revascularized from hepatic arterial system. Diabetes. 1989;38 Suppl 1:192-5. 